\title{
CIÊNCIA \& TECNOLOGIA: APROXIMAÇÕES E DISTANCIAMENTOS DE TERMINOLOGIAS RELACIONAIS
}

\author{
DIEGO SALCEDO \\ Universidade Federal de Pernambuco \\ Recife, Pernambuco, Brasil \\ E-mail: salcedo.da@gmail.com
}




\title{
CIÊNCIA \& TECNOLOGIA: APROXIMAÇÕES E DISTANCIAMENTOS DE TERMINOLOGIAS RELACIONAIS
}

Resumo: Considera que produzir e transmitir conhecimento científico e tecnológico é prática inerente ao fazer ciência. Por meio de revisão da literatura indica os distanciamentos e as aproximações de alguns termos utilizados nessas práticas. Discute aspectos políticos da esfera científico-tecnológica para, em seguida, explorar as terminologias e seus usos. Sugere, por fim, algumas reflexões acerca das atuais práticas de comunicação científica.

Palavras-chave: Ciência; Comunicação científica; Tecnologia.

\section{CIENCIA \& TECNOLOGÍA: SIMILITUDES Y DIFERENCIAS EN LAS TERMINOLOGÍAS RELACIONALES}

Resúmen: Considera que producir y transmitir el conocimiento científico y tecnológico es práctica inherente del hacer ciencia. Por medio de revisión de la literatura indica distancias y aproximaciones de algunos términos utilizados en esas prácticas. Discute aspectos políticos de ámbito científico-tecnológico para, luego, explorar la terminología y sus usos. Sugiere, por fin, algunas reflexiones sobre las prácticas actuales de la comunicación científica. Palabras-clave: Ciencia; Comunicación científica; Tecnología.

SCIENCE \& TECHNOLOGY: SIMILARITIES AND DIFFERENCES IN RELATIONAL TERMINOLOGY

\begin{abstract}
Considers that to produce and transmit scientific and technological knowledge is an inherent practice in making science. Through literature review indicates some detachment and approximation of some terms used in these practices. Discusses political aspects of scientific-technological sphere to, then, explore the terminology and its uses. Suggests, therefore, some reflections about the current practices of science communication.
\end{abstract}

Keywords: Science; Scientific Communication; Technology. 


\section{INTRODUÇÃO}

Explorar as práticas de comunicação científica sugere considerar o campo de produção, circulação e consumo do conhecimento científico e tecnológico (C\&T). Nesse sentido, parece que esse campo contempla, ao mesmo tempo, conceito e prática, atributo discursivo e, segundo Medawar (2008, p. 10) "empreendimento humano". Têm um caráter polissêmico a ponto de ser, historicamente, alvo de tempestuosos debates escolásticos.

A estreita relação entre a Ciência e a Tecnologia é tema das agendas políticas e econômicas da grande maioria dos países. Relação tão complexa que acarretou o surgimento dos neologismos tecnociências ou sóciotecnocientíficas. Parece ser consenso que os produtos resultantes das práticas científicas e tecnológicas são, ao mesmo tempo, as glórias e as indigências de nosso tempo. Destarte, essa relação tem gerado amplos debates e pontos de vista variados. Não poderia ser de outra forma.

De forma alguma temos a pretensão ou a ingenuidade de discorrer sobre essa direção no intuito de esgotar a multiplicidade de leituras e interpretações. Buscamos, apenas, nos situar com relação aos debates com o objetivo de andar numa direção que ofereça os alicerces necessários à construção do nosso caminho, qual seja indicar os distanciamentos e as aproximações de alguns termos utilizados no fazer científico. Assim, exploraremos, por meio de revisão bibliográfica alguns aspectos políticos da esfera científico-tecnológica para, em seguida, explorar as terminologias e seus usos. Por fim, sugeriremos algumas reflexões acerca das atuais práticas de comunicação científica.

\section{POLÍTICA EM CIÊNCIA E TECNOLOGIA}

No Brasil, até os dias de hoje, a relação entre a ciência e a tecnologia ainda parece ser mal compreendida, estranha e distante do imaginário social. Realidade que não podemos atribuir aos privilegiados que compartilham do âmbito escolástico. Motoyama (2004, p. 17), acredita que por C\&T

serem engrenagens essenciais do processo de desenvolvimento econômico e social da atualidade, bem ou mal, elas habitam o nosso cotidiano sem, no entanto, tornar-se parte de nossa cultura mais geral. Pior: no seio da população brasileira, corre solta a lenda de que as atividades de C\&T não são para nós, mas dos outros, dos estrangeiros, dos naturais do Hemisfério Norte, abençoados pelo pensamento científico e pela habilidade tecnológica. 
Para além dessa reflexão, o autor pondera que "a ciência se constitui em aventura palpitante com o objetivo de desvendar o desconhecido [...], a tecnologia é o expediente mais eficaz para solucionar impasses e problemas" e pergunta: “...quem disse que o processo histórico vivido pelo país nada tem a ver com a pesquisa científica e tecnológica"?

Assim também pondera Izquierdo (2005, p. 114) quando afirma que “o desinteresse e desconhecimento da população brasileira sobre a ciência e a tecnologia causa um empecilho para o seu desenvolvimento e redução de sua independência econômica". Além disso, o autor (2005, p. 114) acredita que existe uma forma de preconceito arraigada na sociedade brasileira ao comentar que "o Brasil conhece pouco sobre ciência porque há uma crença de que isto é 'coisa de primeiro mundo' e ignora-se a realizada no país”.

De fato, esses autores não estão completamente equivocados. Não foi no Brasil ou, ainda, na América Latina que ocorreu a formação do pensamento científico moderno nos séculos XVI e XVII, que desestruturou as culturas medievais acarretando a emergência da burguesia, do capitalismo e do que Rosa (2005, p. 38) chama de "Primeira Revolução Científica". Tampouco foi aqui que ocorreu a Revolução Industrial no século XVIII, ou a "Revolução tecnocientífica do século XIX”, como afirma ROSA (2005, p. 38).

Da mesma maneira, não foi nas terras brasileiras que surgiram as transformações do pensamento científico do século XX. No entanto, no Brasil, existiram momentos de práticas científicas e tecnológicas, aqui e acolá, de forma tímida e isolada, mas presente e manifestada como explica Motoyama (2004, p. 18):

criada e plasmada dentro de uma tradição colonial e de dependência, agravada pela economia baseada no regime escravocrata, a cultura brasileira moldou-se no âmbito do retórico e do literário, não se ocupando muito das coisas de C\&T. Já que o trabalho e a técnica eram atribuições de escravos, a elite nacional desprezava as atividades manuais [...]. Contudo isso não significa que não tenha havido em nossas terras manifestações brilhantes de aptidão técnica e gênio científico.

Se levarmos em consideração as palavras de Resende (2005, p. 6), o qual afirma que

o desenvolvimento social e econômico de uma nação está fortemente vinculado ao progresso científico e tecnológico e à situação da educação da população. O conhecimento em ciência e tecnolo- 
gia é, hoje, um dos principais instrumentos de superação das desigualdades...,

e as reflexões de Haddad (2005, p. 11), ao enfatizar que

se é preciso fomentar e investir no desenvolvimento científico e tecnológico, também é indispensável democratizar e direcionar a ciência e a tecnologia para o atendimento das demandas locais, contribuindo para o enfrentamento das desigualdades regionais e sociais do país, o que demanda uma ação sistêmica na educação, com políticas de acesso e qualidade em todos os níveis e modalidades de ensino, da alfabetização à pós-graduação [...]. A educação é o alicerce para a inclusão social, geração de trabalho e renda e para o desenvolvimento científico e tecnológico do país.

Então, não basta aceitar as controvérsias sobre a C\&T. É necessário analisar essas dicotomias de maneira abrangente e multissetorial, com enfoques interdisciplinares capazes de articular dimensões múltiplas, sejam elas no campo da educação, da economia ou da política, sejam elas no contexto regional, nacional e internacional, ou fundamentadas sob a articulação da teoria com a prática. Ou seja, se tomarmos o que foi explanado como premissa básica devemos perceber a C\&T enquanto objeto cultural. Também, como uma forma de instituição de significados e de produção, controle e distribuição social de bens simbólicos.

Conforme Marteleto (1995, p. 1),

essa construção não é arbitrária. Ela só se torna possível pelas realidades sócio-históricas, ou seja, pela consideração não apenas dos sujeitos, suas práticas e representações, mas ainda das estruturas e situações em que se encontram envolvidos. E trata de estudar e entender o modo de funcionamento de uma cultura informacional.

Por outro lado, vale ressaltar que esse discurso político-institucional, sobre modelos de inclusão social, tem seus críticos. Segundo Demo (2005, p. 36)

é isto inclusão social? Facilmente aceitamos como inclusão social a inclusão na margem. Os pobres estão dentro, mas dentro lá na margem, quase caindo fora do sistema. Continuam marginalizados. O que mudou foi a maquiagem da pobreza. Alguns falam de política social [...] para indicar que, em vez de os programas construírem condições emancipatórias, bastam-se com repasse de restos e isto favorece, ao final, os donos do poder. 
Os debates também devem considerar que a $C \& T$ faz parte de realidades culturalmente e socialmente construídas, admitindo as múltiplas e variadas interdependências implicadas nessa consideração. Afirmamos isso, pois cremos que ela constitui parte da simbolização do humano sobre a realidade. Ao afirmamos isso, então, estamos assumindo uma postura de politização da C\&T. A sua articulação com a sociedade ocorre por múltiplos canais, diversos e distintos meios e em dupla via de comunicação. No Brasil, um excelente exemplo disso está registrado num compêndio de entrevistas dadas por Renato Archer, publicadas no livro que leva seu nome (ROCHA FILHO e GARCIA, 2006).

Como afirma Rocha Filho e Garcia (2006, p. 18), "Renato Archer é, possivelmente, o único político brasileiro cuja trajetória foi marcada, desde os primeiros momentos, pela atuação na área de ciência e de tecnologia, articulando políticas e participando ativamente de sua administração institucional”. A história desse cidadão brasileiro, se confunde com a própria história científica e tecnológica do Brasil, passando tanto pela aprovação do Projeto de Lei para a criação do Conselho Nacional de Desenvolvimento Científico e Tecnológico (CNPq), quanto pela criação do Ministério da Ciência e Tecnologia (MCT), dentre tantos outros feitos.

Essa proposta teórica, constituída de uma faceta claramente social e, portanto, pertinente aos estudos sociológicos de C\&T, encontra subsídio nas sugestões de Chrétien $(1994,78)$ ao afirmar que "a ciência não goza de nenhuma extraterritorialidade com relação à sociedade que a produz e a usa. Ela é uma entre outras atividades sociais, integrada ao funcionamento e ao equilíbrio da vida coletiva". Além disso, o autor (1994, p.79) afirma que

\footnotetext{
...as pesquisas não são atividades puramente espirituais e desencarnadas, elas se inserem nas estruturas de financiamento e difusão, moldam-se nas formas da divisão do trabalho e da competição, curvam-se às normas de controle e produtividade, entram em concorrência e em relação com as outras atividades sociais, técnicas, econômicas, políticas, culturais, etc.
}

Estudar a C\&T envolve, além disso, assumir sua função de variável constituída e constituinte de um sistema complexo e globalizado. Variáveis ramificadas em superfícies não lineares de espaço-tempo, partícipes de rupturas histórico -revolucionárias. Se, a partir disso, entendermos o que disse Nietzsche (1988, p. 47) "a ciência é a humanização das coisas", então temos que a ciência e a tecno- 
logia podem ser identificadas como atividades humanas distintas e desconexas em alguns períodos históricos, mas enquanto práticas indissociáveis em outros.

Nesse sentido, e apesar de Cassirer ter proposto, em meados do século XX, que C\&T é parte simbólica de uma ou várias construções culturais, Thuillier (1990, p. 7, apud, MORAIS, 2007, p. 26), considera ignorada a discussão sobre a ciência enquanto parte de uma cultura construída socialmente, e afirma que "estudar 'ciência' como uma realidade cultural é tratar de aprender sua complexidade”.

Ao passar pela esfera acadêmica, a discussão sobre a C\&T se transforma em subsídio teórico e ganha atributos de neutralidade ou causalidade. Nesse sentido Alberguini (2007, p. 54) enfatiza que

ao longo do tempo, tem havido grande dificuldade, por parte de pensadores, em definir o conceito de Ciência e de conhecimento científico. Não há unanimidade entre os autores sobre a concepção de Ciência e esta muda com o próprio desenvolvimento da Ciência. Os Estudos Sociais da Ciência (ESC) reúnem uma gama de disciplinas que, de formas distintas, tentam dar explicações sobre o "fazer científico". Diferentes concepções do que é Ciência têm sido oferecidas pelas grandes matrizes disciplinares que tratam do assunto: a Filosofia da Ciência, a História, a Sociologia do Conhecimento e a Sociologia da Ciência. As diferenças de posicionamentos levam em conta o valor que é dado à Ciência enquanto produção de conhecimento.

Nós defendemos que existe uma articulação de causalidade entre a C\&T e as decisões político-econômicas. Mesmo assim, permanecem questionamentos de cunho filosófico, por exemplo: ao definirmos a C\&T e considerando os percursos que fez, até que ponto podemos afirmar, com exatidão, que sofreu influência dos processos sócio-históricos ou, por outro lado, que caminha autonomamente? Decerto, não parece adequado reduzir a trajetória histórica da C\&T a, apenas, uma sucessão de idéias, pessoas ou datas desconectadas da realidade construída.

Como mencionamos no início deste escrito, pensamos que podemos nos posicionar com relação aos debates sobre C\&T de forma que possibilite criar subsídios para o nosso estudo. Sendo assim, destacaremos três aspectos que podem auxiliar no entendimento desses debates sobre a $C \& T$ e situar o nosso posicionamento.

Consideraremos, inicialmente, que a C\&T está culturalmente imbricada no sistema capitalista mundializado. Castells (2002, p. 51) mostra isso quando estudou o 
surgimento de uma nova estrutura social, manifestada sob várias formas conforme a diversidade de culturas e instituições em todo o planeta. Essa nova estrutura social está associada ao surgimento de um novo modo de desenvolvimento, o informacionalismo, historicamente moldado pela reestruturação do modo capitalista de produção, no final do século XX.

As práticas de produção, distribuição e consumo de bens e serviços, além dos modelos educacionais, são constantemente permeados por culturas tecnocientíficas e estão baseadas, do ponto de vista histórico, em nexos mercantilistas eurocêntricos que remontam aos séculos XVI e XVII.

Nesse sentido argumenta Dupas (2001, p. 100), "o capitalismo global caracteriza-se por ter na inovação tecnológica um instrumento de acumulação em nível e qualidade infinitamente superiores aos experimentados em suas fases anteriores". Esse sistema interpreta os significados, as aplicações e o somatório de conhecimentos dessas culturas, além de apropriar-se delas para sua própria reprodução.

A rigor, a tecnologia não precisa ser nova ou complexa, mas, nas sociedades modernas, o termo vem ganhando conotação de algo novo e significativamente mais avançado, sob a forma de novos bens e processos de produção, distribuição e utilização (ROSENTHAL, apud, PINHEIRO; PINHEIRO, 2002, p. 157).

A segunda posição considera o fato de que a $C \& T$ tem um valor potencial enorme para a construção da realidade social que permite flexibilidade, continuidade e aplicabilidade nos distintos setores sociais. A partir de pressupostos que tangenciam fronteiras de diversas e distintas áreas do conhecimento, essa articulação pode ser estudada e debatida partindo de pressupostos da Sociologia da Ciência e da Tecnologia, com maior enfoque sobre os processos de comunicação de C\&T, tanto do ponto de vista das instituições e das sociedades científicas ou colégios invisíveis, quanto dos sistemas de comunicação, difusão e educação científica.

O terceiro posicionamento diz respeito à impossibilidade e à inadequação, apesar de não ser o foco deste trabalho, de analisar os conceitos ciência e tecnologia, sem considerar a sua correlação com os campos políticos, econômicos, ecossistêmicos, éticos e históricos, articulados aos pressupostos teóricos propostos no âmbito escolástico. 


\section{APONTAMENTOS HISTÓRICOS SOBRE A COMUNICAÇÃO CIENTÍFICA}

A partir do que foi exposto admitiremos que não será necessária, para este artigo, uma ampla explicação sobre a História da Técnica, da Ciência ou da Tecnologia e suas articulações com os processos sociais. Outrossim, pensamos que dois pontos básicos merecem um pouco mais de atenção, considerando a problemática e a proposta temática abordada aqui.

Para tanto, consideraremos que a prática científica, a partir do século XVII, deixa de ser uma atividade, exclusivamente, filosófica e passa a fazer parte de uma força produtiva, associada a interesses políticos, militares e econômicos. A tecnologia, por sua vez, acompanhará o desenvolvimento dessas práticas científicas, não apenas produzindo um avanço com relação às técnicas anteriormente estabelecidas, mas tecendo um processo histórico em que certas características são bem definidas, como por exemplo, a institucionalização das forças produtivas e a exploração científica e econômica.

O período descrito como Moderno ou da Ciência Moderna pode ser caracterizado, dentre outros aspectos, pelo o aumento da produção de material impresso e pelo crescimento populacional interessado no avanço dos conhecimentos e de suas aplicações. Essas foram algumas das múltiplas causas que possibilitaram o surgimento das primeiras sociedades científicas e dos primeiros periódicos científicos.

Braga (2004, p. 44) sugere que

ao contrário da tradição hermética da Idade Média, na qual um saber como o dos alquimistas pertencia a uns poucos iniciados, a ciência moderna nasceu no contexto de um amplo processo de divulgação, pois ela necessitava conquistar corações e mentes para o novo saber. O surgimento de uma nova forma de ver o mundo e de pensar não poderia se constituir sem uma rede de difusão.

As sociedades científicas foram criadas, em meados do século XVII, a partir da necessidade de que a investigação científica fosse organizada institucionalmente. Segundo Sabbatini (2005, p. 47)

começando como associações que agrupavam pessoas interessadas em determinados temas, patrocinadas pelas universidades, por mecenas ou por figuras de destaque, tinham como principal objetivo facilitar a comunicação e a discussão dos novos conhecimentos de uma forma mais direta que permitiam os livros. 
Assim, como o decorrer dessa prática e aumento do número de participantes nas discussões e nos estudos, muitas das sociedades científicas foram transformadas em academias de renome nacional. As primeiras academias, ainda segundo Sabbatini (2005, p. 47), foram "a Academia del Lincei (1600-1630), em Roma, seguida pela Academia del Cimento (1651-1657) [...], em seguida vieram a Royal Society (1622), de Londres e a Académie dés Sciences, na França".

Fica evidente que foi a partir desse século que a ciência passou a ser uma atividade institucionalizada e controladora das investigações filosófico-empíricas. Assim, sugere Bernal (1989, apud, Sabbatini, 2005, p. 48):

...que a ciência fora convertida em uma instituição, e uma instituição com os distintivos, a solenidade, e desgraçadamente, com certa dose de pompa e pedantismo que tinham outras instituições mais antigas como o direito e a medicina. As sociedades [científicas] se transformaram em uma espécie de tribunal da ciência, e um tribunal de autoridade suficiente para excluir dela muitos loucos charlatães difíceis de distinguir dos verdadeiros científicos para o público em geral, porém também, desafortunadamente, tinham autoridade para excluir, ao menos por um tempo, muitas idéias revolucionárias da ciência oficial.

Foi nesse novo contexto que, de dentro dessas sociedades, surgiram os primeiros periódicos científicos. Tinham como objetivo comunicar essa neófita ciência entre os estudiosos, como ela procedia, quais eram as aplicações metodológicas e quais os resultados obtidos. Num primeiro momento essa comunicação era realizada pelo sistema de missivas postais chamado, Republique des Letters.

Com o crescimento exponencial do volume de informações, escrever cartas não cobria mais o escopo necessário à atualização dos pesquisadores, fazendo com que a imprensa fosse, então, utilizada como mecanismo para solucionar esse problema. Assim, em meados de 1650, a utilização da imprensa foi expandida em direção aos intelectuais, pensadores, professores e cientistas. Devemos salientar que a comunicação científica por meio dos periódicos apenas visava a substituir a utilização das cartas, no entanto a sua função era a mesma.

Conforme Sabbatini (2005, p. 51), "os periódicos acadêmicos tornara-se realidade em 1665, com o surgimento do Journal des Sçavans, na França, sendo logo seguido pelo Transactions of the Royal Socitey of London, no mesmo 
ano". Com o advento dessas e de outras publicações posteriores, é possível perceber que houve um foco de interesse mútuo entre autores. Assim, um debate específico teve início, originando as disciplinas específicas que, antes, eram centradas num discurso universal e, absolutamente, objetivo, além de possibilitar a emergência e um novo espaço discursivo.

Concordamos com a afirmação de Sabbatini (2005, p. 52) ao propor que

podemos perceber que as publicações científicas têm suas raízes em uma revolução do conhecimento humano, estando profundamente ligadas aos métodos epistemológicos da ciência moderna e ao desenvolvimento das estruturas sociológicas e organizacionais sobre as quais ela iria se assentar. ${ }^{1}$

Durante o século XIX, paralelamente ao crescimento exponencial desse conhecimento, houve uma ampliação e aprimoramento das ferramentas de difusão dos saberes. Esse vertiginoso aumento de produção bibliográfica nos leva a pensar numa explosão da informação científica, propriamente dita. Esses meios de divulgação acompanharam as sociedades ou comunidades científicas e, de certa forma, ainda o fazem.

Esse crescimento infindável de bibliografia científica acarretou a análise de pensadores como Ortega y Gasset (2006, p. 40) que, no famoso Encontro Internacional de Bibliotecários, em Barcelona (1935) já vislumbrava uma das maiores problemáticas dos tempos modernos.

Já há livros em demasia. Mesmo reduzindo bastante o número de temas a que cada homem dedica sua atenção, a quantidade de livro que ele precisa absorver é tão gigantesca que supera os limites de seu tempo e sua capacidade de assimilação. A mera orientação na bibliografia de um assunto representa hoje para cada autor um esforço considerável, em que perde muito tempo. Mas, uma vez despendido esse esforço, constata que não poder ler tudo o que deveria ler. Isso o leva a ler às pressas, e a ler mal e, ademais, deixa -o com uma impressão de impotência e fracasso, ao fim e ao cabo, de ceticismo em relação à sua própria obra.

Sobre essa situação, Fonseca (1973, p. 23) explica que "as informações

1 Diante dessa constatação e apesar de estarmos cientes que seria inadequado desconsiderar a questão sociológica que está envolvida nos estudos sobre a comunicação, a difusão e a educação científica, não será possível, neste trabalho, tratar sobre essa relevante perspectiva teórica. De certo, esse campo será explorado em trabalhos futuros. 
divulgadas pelos milhões de documentos gráficos produzidos em todo o mundo são tantas e tão pouco acessíveis que o moderno especialista não tem mais tempo para manter-se atualizado em relação ao que se passa no campo de sua especialização". Não obstante, com o advento da Internet e os serviços tecnológicos que ali estão, é possível, ainda que exista uma vasta literatura que jamais será acessada, realizar investigações acadêmicas e cobrir um escopo bibliográfico suficiente à produção de conhecimento científico.

Nos termos de Landi (2004, p. 25-26) existe uma importância fundamental na difusão do conhecimento da C\&T e que foi assim explicada no $1^{\circ} \mathrm{Con}$ gresso Internacional de Divulgação Científica, ocorrido em São Paulo no ano de 2004:

...colocaria mais ou menos na seguinte sequência: reduzir as distâncias entre ciência, tecnologia e sociedade; aumentar o conhecimento dos princípios básicos e do equipamento social do mundo moderno para que a sociedade possa utilizá-lo, não como mágica, mas como ferramenta de trabalho. Tem uma importância muito grande também como prestação de contas. A sociedade é a grande contribuinte para que esse sistema funcione e a ela nós devemos prestar contas do que acontece em nosso meio, na ciência e tecnologia. E a divulgação científica é a melhor demonstração de que somo capazes de fazer pesquisas de qualidade. $O$ terceiro ponto, é o apoio da aculturação da inovação, a importância de que uma cultura se estabeleça na nossa sociedade como forma de garantir a continuidade dos orçamentos que se destinam a esse sistema. Se não tivermos a sociedade nos apoiando, teremos mais dificuldades. O convencimento da classe política se faz à medida que seus eleitores pressionam o sistema nessa direção. $O$ quarto é a auto-estima os nossos pesquisadores, pois, quando se difunde aquilo que se faz de qualidade em nosso país, há uma afirmação permanente de que somos capazes de realizar pesquisa de qualidade. O quinto é a própria democratização do conhecimento. Discussões desse mundo moderno, complexo, como clonagem e produtos geneticamente modificados, não podem ficar nas mãos de decisões que ignorem a sociedade. A sociedade precisa dominar esses procedimentos para tomar as decisões. O processo de difusão tem uma importância enorme para que se atinjam e se formulem essas decisões.

Posto isso, parece salutar indicar algumas características de distanciamento e aproximação com relação a cada uma das expressões que são utilizadas nos estudos que tratam dos sistemas de comunicação da C\&T, 
a saber: comunicação, difusão, disseminação e divulgação científica, assunto tratado a seguir.

\section{APROXIMAÇÕES E DISTANCIAMENTOS DA TERMINOLOGIA NA CO- MUNICAÇÃO CIENTÍFICA}

Essas expressões se referem tanto a uma prática social, estabelecida e padronizada no cerne acadêmico, quanto a conceitos que são estudados em áreas como a Sociologia da Comunicação, a Ciência da Informação e a Comunicação Social, para citar algumas.

Gomes (2000, p. 3-4) defende que no estudo dessas expressões "a bibliografia brasileira e a internacional estão orientadas antes para aspectos técnicos operacionais do que para a dimensão taxionômica". O que geralmente ocorre é que o enfoque dos autores para distinguir os conceitos foca no público e na linguagem, mas não nos media ou nos modos de produção.

Por um lado, Massarani (1998, p. 14) afirma que muitas vezes a expressão divulgação científica é utilizada inadequadamente como sinônimo de outras expressões como "difusão científica, disseminação científica, vulgarização científica, popularização da ciência e comunicação pública da ciência”. Por outro, Alberguini (2007, p. 57) sugere que "tais especialidades, ao longo da história, ora se convergem, ora se distanciam. Em diversos momentos, cada uma dessas especialidades apresenta um corpus conceitual bem delimitado, em outros, são tomados como sinônimos".

Conforme Menzel (1968, apud, SABBATINI, 2005, p. 62), a comunicação científica pode ser definida como a "totalidade das publicações, facilidades, ocasiões, acordos institucionais e hábitos que afetam direta ou indiretamente a transmissão de mensagens científicas entre cientistas". Fica claro que se trata de um tipo específico de sistema comunicativo e, por tanto, gerenciado por um grupo específico de atores sociais. No entanto, não é tão simples assim.

Nesse sentido, afirma Chrétien (1994, p. 119, apud, MORAIS, 2007, p. 39):

a ciência não é um enclave de harmonia e de transparência, devotada ao culto exclusivo do espírito, num materialista e dividido. Ela está presa, ao contrário, em todas as redes, indústrias, financeiras, ideológicas, políticas, estratégicas, etc., que estruturam ou desestruturam a sociedade global.

Por outro lado, uma contrapartida é verificável com relação a essa asser- 
tiva. Uma espantosa incultura de grande parte da população, daqueles que o Ministro chamou de "excluídos". Além disso, convém afirmar que parte dessa dicotomia, entre o avanço da C\&T e da percepção pública da C\&T, passa pelo campo da educação.

Meadows (1999, p. 1), propõe que "a maneira como o cientista transmite informações depende do veículo empregado, da natureza das informações e do público-alvo". Ainda nesse sentido o autor complementa (1999, p. 2): "O meio disponível e a natureza da comunidade científica afetam não só a forma como a informação é apresentada, mas também a quantidade de informações em circulação". A natureza atual da ciência é multidisciplinar e leva cientistas de todo o mundo a desenvolverem redes de comunicação do tipo formal e informal, com o intuito de trocar informações e possibilitar o progressivo desenvolvimento da investigação científica.

A partir disso, segundo Epstein (2002, p. 98),

...torna-se necessário fazer uma clara distinção entre os principais gêneros de comunicação científica, a comunicação primária e a comunicação secundária. A comunicação primária é aquela realizada entre os cientistas e que tem por objetivo estabelecer o intercâmbio de informações em um âmbito restrito e que também pode ser denominada de disseminação. Já a comunicação secundária é realizada entre cientistas e o público leigo, diretamente ou por meio da mediação de divulgadores científicos, e se preocupa com a divulgação do conhecimento científico para a sociedade. A comunicação secundária é mais comumente referida como divulgação.

Como efeito dessa prática de comunicação científica, novos conhecimentos são gerados, criando possibilidades para que ocorra a inovação nos processos de produção e no desenvolvimento de serviços e produtos. Zamboni (2001, p. 34) afirma que

nesse sentido, as publicações e as reuniões são instrumentos fundamentais para mediar as relações que se efetuam no seio da irmandade científica. Ambos constituem fóruns privilegiados para anunciar resultados, receber contribuições, ouvir críticas, submeter a julgamentos, enfim, dar continuidade ao processo evolutivo do conhecimento.

Dessa forma, percebemos como o processo comunicativo, seja ele formal ou informal, é essencial à natureza e a prática da C\&T. Segundo Russel (2001, p. 1, informação eletrônica), 
os cientistas não apenas relatam os resultados para os seus colegas através de artigos publicados, de preprints eletrônicos e apresentações em eventos, mas dependem também de conhecimento dos trabalhos publicados anteriormente para formular propostas e metodologias de investigação. A troca de ideias e informações com os pares é uma parte essencial da fase experimental. Assim, a comunicação está presente em todas as fases do processo de pesquisa.

Complementando o que disse essa autora, os estudos em comunicação científica, dentre outros assuntos, podem tratar sobre o sistema comunicativo entre pesquisadores (pares), analisando como os cientistas de qualquer área de conhecimento utilizam e trocam informações, relevantes às pesquisas, por meios formais e informais. Os meios formais seriam, conforme sugere Cunha (2001, apud, ALVIM, 2003, p. 58):

textos introdutórios, monografias especializadas, estados da arte, teses e dissertações, relatórios de pesquisa, artigos científicos, periódicos científicos, sumários correntes de periódicos, anais de eventos, livros, revisões bibliográficas, serviços de resumo, serviços de indexação, bibliografias correntes e retrospectivas, catálogos, manuais, guias, normas técnicas e patentes. literatura cinzenta e os Anais de eventos.

Somados a esses meios, Alvim (2003, p. 59) afirma que

esse conjunto vem sendo ampliado, pois com a incorporação das formas de comunicação utilizando os recursos audiovisuais e multimídia se agregam filmes, vídeos, discos, CDs, fitas, mapas, peças de museu, herbários, arquivos e coleções científicas. Esses meios começam a ser digitalizados, criando a convivência de meios impressos e eletrônicos, que ampliam a capacidade de disponibilização da comunicação científica.

Os meios informais seriam as conversas, as correspondências, os e-mails, jornal, revistas, televisão, rádio, cinema, história em quadrinhos e, também, o cartão-postal, o máximo-postal, a fotografia, os "selos postais" (SALCEDO, 2010), e muitos outros. Assim, esses meios formais e informais de comunicação científica fariam parte da classificação proposta por Epstein, anteriormente citada, em que a utilização de códigos linguísticos específicos, destinados a um público seleto se acomoda no conceito de disseminação científica. Massarani e Moreira (1990, p. 32) têm uma visão que complemen- 
ta a proposta de Epstein. Para os autores, a comunicação científica pode ser dividida em três linhas:

\begin{abstract}
os discursos científicos primários (escritos por pesquisadores para pesquisadores), os discursos didáticos (como os manuais científicos para ensino) e os da divulgação científica. Em todos eles, embora com conteúdos lexicais, estilos e formatos variados, cada discurso serve a um propósito determinado e busca atingir um público específico.
\end{abstract}

Pasquali (1978, apud, MASSARANI, 1998, p. 18) teve a preocupação de distinguir três conceitos que são ratificados, tanto por Wilson Bueno (1984, apud, GOMES, 2000, p. 23), quanto por Calvo Hernando (2006, apud, ALBERGUINI, 2007, p. 58):

Difusão é o envio de mensagens elaboradas em códigos universalmente compreensíveis para a totalidade das pessoas.

Disseminação é o envio de mensagens elaboradas em códigos especializados a receptores selecionados e restritos, formado por especialistas.

Divulgação é o envio de mensagens elaboradas mediante a transcodificação de linguagens, transformando-as em linguagens acessíveis.

No entanto, Gomes (2000, p. 24) cita que Bueno não concorda com Pasquali com relação ao conceito de difusão científica, posto que,

Bueno o entende como um hiperônimo que incorpora a disseminação científica (difusão para especialistas) e a divulgação científica (difusão para o público em geral), ao passo que Pasquali vê difusão como sinônimo de divulgação. No que se refere às características gerais da disseminação e da divulgação, esses dois autores têm posições semelhantes.

Além disso, na visão de Bueno, a divulgação inclui, além de veículos midiáticos, livros didáticos, aulas de ciência e histórias em quadrinhos, entre tantos outros. Por sua vez, Hernando (2000, informação eletrônica) discor- 
da de tal compreensão e interpreta que a divulgação científica compreende as atividades de ampliação do conhecimento fora do âmbito escolar e acadêmico, de forma que aulas de ciência não se constituem uma forma de divulgação.

Para além desse debate teórico sobre o significado e aplicação da terminologia adequada, Oliveira (2005, p. 13) percebe que

[...] o acesso às informações sobre C\&T é fundamental para o exercício pleno da cidadania e, portanto, para o estabelecimento de uma democracia participativa, na qual grande parte da população tenha condições de influir, com conhecimento, em decisões e ações políticas ligadas a C\&T. Entendemos que a formação de uma cultura científica [...] não é processo simples [...]. No entanto, o acesso às informações sobre C\&T como um dos mecanismos que pode contribuir de maneira efetiva para a formação de uma cultura científica deve ser facilitado ao grande público carente delas

Afinal, sem divulgação, difusão ou popularização de práticas de C\&T, as pessoas que não participam do ambiente escolástico, permanecerão desinformadas com relação às descobertas de $C \& T$ e suas aplicabilidades sociais, a quem são os pesquisadores e suas atividades. Logo, a comunicação científica tem um relevante papel social, tanto para a continuidade da prática de C\&T, quanto para o compartilhamento de distintos saberes.

Nessa mesma direção, Gomes e Salcedo (2005, p. 81) afirmam que

comunicar conhecimentos gerados nas instituições de pesquisa é difundir informações para que a comunidade científica possa desenvolver e aprofundar os conhecimentos e também para que a sociedade tome ciência do papel desses conhecimentos na melhoria de sua qualidade de vida.

Perpassando pela perspectiva de que os efeitos da produção e circulação de conhecimento em C\&T podem ser meios essenciais para o desenvolvimento econômico e social, Baumgarten (2008, p. 3, grifo nosso) comenta sobre a problemática da apropriação social do conhecimento:

a avaliação de CT\&l (ciência, tecnologia e inovação) e a divulgação científica são importantes vetores da relação entre conhecimento e desenvolvimento social e econômico que podem ser melhor apreciados através de análise dos entrelaçamentos entre políticas de C\&T, disponibilidade de informação sobre C\&T, potencialidades 
da divulgação científica para a ampliação do debate público sobre as possibilidades e obstáculos para a apropriação de C\&T pela sociedade.

No entanto, existem críticas com relação ao atual modelo de difusão da C\&T. Hilgartner (1990, apud ALBERGUINI, 2007, p. 60) defende que

...a visão culturalmente dominante de popularização da Ciência é enraizada na noção de um conhecimento científico puro e genuíno com o qual o conhecimento popularizado é contrastado. É assumido, segundo ele, um modelo de dois estágios: primeiro, os cientistas desenvolvem um conhecimento científico genuíno subseqüentemente, os divulgadores relatam tais conhecimentos para o público.

$[\cdots]$

Essa visão, para Hilgartner (idem), sugere que as diferenças entre o conhecimento genuíno e a Ciência popularizada devem ser causadas por "distorção" ou "degradação" da verdade original. Para o autor, essa visão encara a popularização do conhecimento, na meIhor das hipóteses, como uma atividade educacional de simplificação da Ciência para não especialistas e, na pior, como "poluição", "distorção" do conhecimento. Segundo o autor, essa visão apresenta problemas conceituais por ser extremamente simplificadora do processo de comunicação. Essa visão dominante, segundo Hilgartner (ibidem), serve aos cientistas (e a outros que derivam sua autoridade do conhecimento especializado) como um recurso no discurso público, fornecendo um repertório de dispositivos retóricos para interpretar a Ciência para leigos, e uma ferramenta poderosa para sustentar a hierarquia social dos especialistas.

Essa mesma visão também serviu para que Derrida (apud, Kreinz, 2002, p. 8) "coloca-se em questão a autoridade do código e o poder da escritura" acarretando uma crítica direta ao problema da ética da divulgação científica. Esse autor francês sugere um "ato de violência" escondido na neutralidade do discurso científico. Conforme Kreinz (2002, p. 9), Derrida duvida sobre qual é "o papel e o lugar da imparcialidade, ou do enunciado que se diz científico, como se houvesse uma concordância universal em torno de determinadas verdades da ciência". 
Por outro lado, Carvalho (2003, p. 17) propõe uma difusão de C\&T que reconstrói, adapta, simplifica e explica o discurso científico "a partir de meios, formatos e linguagens adequados ao público em geral”. Acreditamos que apresentar resultados de investigações científicas à sociedade é algo próprio da prática científica, mesmo que seja necessária uma discussão de como é veiculado o conteúdo científico à população.

É assim que a base de conhecimentos da humanidade permanece, de certa forma, atualizada e articulada com o conhecimento pretérito, mesmo que nessa prática exista um "ato de violência", por meio da linguagem. Nas palavras de Pavan (2002, p. 62) essa "é a ética e o desafio, no século XXI, da divulgação científica". É extremamente relevante para a sociedade ter acesso ao conhecimento científico, tornando-se também evidente o papel social da mediação dessa informação.

\section{CONSIDERAÇÕES FINAIS}

É fato que as pessoas vêm, com o passar do tempo, buscando cada vez mais informações e conhecimentos, de modo que possam construir seu pensamento crítico acerca de assuntos que envolvam as tomadas de decisões dos principais fatores de desenvolvimento socioeconômico do país. É nesse ponto que existe uma responsabilidade ético-social dos pesquisadores e cientistas em Ihes oferecer informações necessárias para que se tornem cada vez mais capazes de racionalizar sobre suas vidas e o ambiente em que vivem.

A partir da revisão da literatura, de forma alguma com pretensões de exaustividade, e de alguns apontamentos reflexivos é defendida a ideia de que apesar das aproximações e distanciamentos dos termos utilizados no fazer científico e tecnológico, sem difusão do conhecimento científico não há impacto social. De certo, tema que demanda amplo debate público, posto que, se assim não ocorrer os indivíduos persistirão na sua ignorância por não terem acesso a esse tipo de conhecimento.

Assim, é salutar, para além da questão terminológica, crias as condições e promover melhores estruturas de articulação com o intuito de difundir o pensamento e os resultados das investigações científicas, criando fluxos e consumo de informação, visando ao cidadão comum, prática social fundamental para o avanço dos conhecimentos humanos.

Por fim, este escrito indica a necessidade de continuidade dos trabalhos de pesquisa com vistas a explorar outros elementos relevantes para aprimo- 
rar o debate sobre o papel social atrelado às pesquisas científicas realizadas e como elas são disseminadas e divulgadas. Tudo isso pode servir para que um pensar estratégico seja interposto junto aos planejamentos já existentes, particularmente, no que diz respeito aos novos modos de produção, circulação e disseminação do conhecimento científico e tecnológico.

\section{REFERÊNCIAS}

ALBERGUINI, Audre Crictina. A ciência nos telejornais brasileiros: o papel educativo e a compreensão pública das matérias de CT\&I. São Paulo: UMESP, 2007. Tese de Doutorado.

ALVIM, Paulo César R. Comunicação da ciência. In: DUARTE, Jorge; BARROS, Antonio Teixeira de. (Orgs.). Comunicação para ciência, ciência para comunicação. Brasília: EMBRAPA, 2003. p. 47-66.

BAUMGARTEN, Maíra. Ciência, tecnologia e inovação: construindo a sociedade do conhecimento. In: Reunião Anual da SBPC. 60., 2008, São Paulo. Registros eletrônicos... Campinas: UNICAMP, 2008. Disponível em: <sbpcnet.org.br/livro/6ora/textos/ SI-Ma\%EdraBaumgartenCorrea.pdf $>$. Acesso em: 20.12.2009.

BRAGA, Marco; GUERRA, Andréia; REIS, José Cláudio. Breve história da ciência moderna. Rio de Janeiro: Zahar, 2004, v. 2.

CALVO HERNADO. Hacia una teoría de la comunicación de la ciencia. Periodismo CientífCO, Madrid, n. 30, 2000.

CARVALHO, Alessandra Pinto de. A divulgação e o marketing da Ciência. uma análise do documentário como instrumento híbrido de comunicação científica pública. São Paulo: UMESP, 2003. Tese de Doutorado.

CASTELLS, Manuel. A sociedade em rede. 6. ed. Rio de Janeiro: Paz e Terra, 2002.

CHRÉTIEN, Claude. A ciência em ação: mitos e limites. São Paulo: Papirus, 1994.

DEMO, Pedro. Inclusão digital: cada vez mais no centro da inclusão social. Inclusão Social, Brasília, v. 1, n. 1, p. 36-38, out.-mar., 2005.

DUPAS, Gilberto. Ética e poder na Sociedade da Informação. SP: UNESP, 2001.

EPSTEIN, Isaac. Divulgação científica: 96 verbetes. São Paulo: Pontes, 2002.

FONSECA, Edson Nery da. Problemas de comunicação da informação científica. São Paulo: Thesaurus, 1973.

GOMES, Isaltina Maria de Azevedo Mello. A divulgação científica em Ciência Hoje: uma abordagem discursivo-textual. Recife: UFPE/PPGL, 2000. Tese de Doutorado.

; SALCEDO, Diego Andres. A divulgação da informação científica no Jornal do

Commercio. Ícone. Recife, v. 1, n. 8, p. 80-88, 2005.

HADDAD, Fernando. Educação para induzir e democratizar o conhecimento científico. 
Inclusão Social, Brasília, v. 1, n. 1, p. 10-11, out./mar., 2005.

IZQUIERDO, Iván. Aumentando o conhecimento popular sobre a ciência. In: CONFERÊNCIA NACIONAL DE CIÊNCIA, TECNOLOGIA E INOVAÇÃO: desenvolvendo idéias para desenvolver o Brasil, 3, Brasília. Anais...Parcerias Estratégicas, Brasília, n. 20, parte 1, p. 113-118, jun. 2005.

KREINZ, Glória. Ética, comunicação e divulgação. In: ; PAVAN, Crodowaldo. Ética e divulgação científica: os desafios do novo século. São Paulo: NJR, 2002. p. 7-23. (Divulgação científica, v. 5).

LANDI, Francisco Romeu. Cerimônia de abertura: a importância da divulgação científica. In: KREINZ, Glória; PAVAN, Crodowaldo. Congresso Internacional de Divulgação Científica. São Paulo: NJR, 2004. p. 25-26. (Divulgação científica, v. 7).

MARTELETO, Regina Maria. Cultura informacional: construindo o objeto informação pelo emprego dos conceitos de imaginário, instituição e campo social. Ciência da Informação. Brasília, v. 24, n. 1, 1995. Disponível em: <http://revista.ibict.br/index.php/ciinf/article/view Article/535>. Acesso em 21.12.2009. Não paginado.

MASSARANI, Luisa; MOREIRA, Ildeu e Castro. A retórica e a ciência: dos artigos originais à divulgação científica. Ciência e Ambiente, Santa Maria, n. 1, v. 1, jun. 1998, p. 31-47.

MEADOWS, A. J. A comunicação científica. Brasília [DF]: Briquet de Lemos, 1999.

MEDAWAR, Peter Brian. Os limites da Ciência. São Paulo: UNESP, 2008.

MORAIS, Regis de. Evoluções e revoluções das ciências atuais. Campinas: Alínea, 2007.

MOTOYAMA, Shozo. Prelúdio para uma História: ciência e tecnologia no Brasil. São Paulo: EDUSP, 2004.

NIETZSCHE, Friedrich Wilhelm. A Gaia ciência. São Paulo: Ediouro, 1988.

OLIVEIRA, Fabíola de. Jornalismo científico. 2. ed. São Paulo: Contexto, 2005.

ORTEGA Y GASSET, José. Missão do bibliotecário. Brasília: Briquet de Lemos, 2006.

PAVAN, Crodowaldo. Ciência, sociedade e os desafios do novo século. In: KREINZ, Glória; . Ética e divulgação científica: os desafios do novo século. São Paulo: NJR, 2002. p.

61-68. (Divulgação científica, v. 5).

PINHEIRO, Helano Diógenes; PINHEIRO, Daniel Rodriguez de Carvalho. Tecnologia e inovação nas sociedades capitalistas. Humanidades. Fortaleza, v. 17, n. 2, p. 157-160, ago-dez, 2002.

RESENDE, Sérgio. Conhecimento e inclusão social. Inclusão Social, Brasília, v. 1, n. 1, p. 6-7, out./mar., 2005.

ROCHA FILHO, Álvaro; GARCIA, João Carlos Vitor. (Org.). Renato Archer: energia atômica, soberania e desenvolvimento: depoimento. Rio de Janeiro: Contraponto, 2006.

ROSA, Luiz Pinguelli. Tecnociências e Humanidades: novos paradigmas e velhas questões: o determinismo newtoniano na visão de mundo moderna. São Paulo: Paz e Terra, 2005. v.1. 
RUSSELL, Jane. La comunicación científica a comienzos del siglo XXI. Revista Internacional de Ciencias Sociales. n. 168, jun. 2001. Disponível em: <http://www.oei.es/salactsi/ rusell.pdf >. Acesso em: 17.05.2008.

SABBATINI, Marcelo. Publicações eletrônicas na Internet. São Paulo: Yendis, 2005.

SALCEDO, Diego Andres. A ciência nos selos postais comemorativos brasileiros: 19002000. Recife: EDUFPE, 2010). (Coleção Teses e Dissertações, 48).

ZAMBONI, Lílian Márcia Simões. Cientistas, jornalistas e a divulgação científica. Campinas, Autores Associados, 2001.

\section{Diego Salcedo}

Bacharel em Biblioteconomia (UFPE), Mestre e Doutor em Comunicação (UFPE). Professor no Departamento de Ciência da Informação da UFPE. Atua em ensino, pesquisa, extensão e cultura nos seguintes campos: 1. Comunicação, Divulgação, Linguagem e Discurso das Ciências (especial interesse em Divulgação Científica); 2. História, Filosofia, Tratamento (Indexação), e Discurso de Imagens (Cultura Visual); 3. Ciência da Informação (Teoria e Fundamentos); 4. Documentação e Memória (Teoria, Preservação e Conservação); 5. Documentação Filatélica e Postal (Organização e Tratamento); 6. Colecionismo (Memória, História, Psicologia, Economia, Consumo); 7. Filatelia no Brasil (Memória, História, Política e Economia); 8. Bibliofilatelia (Filatelia, Bibliofilia, História Postal e Selo Postal). 